\title{
Possession Syndrome at High Altitude (4575 m/15000 ft)
}

\author{
Khan ID, Sahni AK
}

Department of Pathology and Molecular Medicine

Army Hospital Research and Referral

New Delhi 110010, India

Corresponding Author

Inam Danish Khan

Department of Pathology and Molecular Medicine

Army Hospital Research and Referral

New Delhi 110010, India

\section{ABSTRACT}

In a first of its kind, a 20 year old Hindu, highlander, working girl presented with abnormal behavior, unrelenting symptoms, had limited benefit by usual treatment and was diagnosed as Possession syndrome. Exorcism offered symptomatic relief. The girl resumed normal activities with no recurrence in a 12 month follow up. Possession syndrome is explained in both medical and theological perspectives. Modern medicine associates it with a mental illness though True Possession syndrome without associated mental illness has been reported. Theological perspective can be amalgamated with current scientific theory and practice, thereby complimenting existing concepts.

Email: titan_afmc@yahoo.com

Citation

\section{KEY WORDS}

Abreaction, acclimatization, exorcism, high altitude, possession

Khan ID, Sahni AK. Possession Syndrome at High Altitude (4575 m/15000 ft). Kathmandu Univ Med J 2013;43(3):253-255.

\section{INTRODUCTION}

Possession syndrome (Spirit/Demonic Possession) is a paranormal diseased state in which a person is said to be possessed by a spirit, demon, animal, extraterrestrial being or disincarnate objects including God, resulting in noticeable changes in health, behavior and appearance. Possession syndrome exists worldwide and has been reported in people with low educational and social status, particularly young females, divorcees, concubines and newly recruited soldiers. Childhood abuse, neglect, isolation, loneliness, environmental difficulties and distressing emotional, social or psychological experiences are implicated. Possession syndrome represents the tip of an iceberg as they are largely dealt by Exorcists and go unreported. An extremely rare case of Possession syndrome in a young girl at 4575 $\mathrm{m} / 15000 \mathrm{ft}$, a first of its kind, is presented here.

\section{CASE REPORT}

A right handed, Hindu, Hindi speaking, highlander, working girl of 20 years, pursuing graduation was fully acclimatized and performing well as a mountaineering trainee in a mountaineering course. After 10 uneventful days at Base Camp (15000 ft), on climbing $2000 \mathrm{ft}$ higher along with course mates and instructors, she reported persistent headache, uneasiness, fear and excessive crying. Headache was moderate and localized over forehead without any associated symptoms. Diagnosed as altitude sickness, the patient was descended and given paracetamol, oral fluids, acetazolamide (Diamox) $250 \mathrm{mg}$ and nursed for an hour in a High Altitude Pulmonary Oedema (HAPO) Bag after which she had partial relief. An hour later, she complained of headache of increasing intensity. Abnormal behaviour was reported by observers. There was no contributory past history during infancy, childhood, adolescence or adulthood or any addictions, physical or mental illness. No noteworthy stressors were found. There was no family history of mental 
illness or drug abuse. She uttered repetitive non coherent sounds in normal tone and volume, unwitting to observers. She maintained a constant sitting posture with extended legs and weight supported on both hands at back. Pulse and blood pressure were high while temperature, respiration and systemic examination were normal. Mental status examination revealed a well kempt girl, not maintaining eye contact, not responding to direct commands, unaware of the environment around her and preoccupied with self. She exhibited rolling eye movements, clenched teeth and moved her head back and forth rhythmically. She could not be evaluated for mood and affect, thought form and content, perception, cognition and insight. She was diagnosed as a case of Possession Syndrome and an early evacuation after stabilization was planned.

Exorcism was conducted over three hours in presence of the first author. After an hour of repetitive direct questioning, the girl identified herself as a male who was a native of Bengal, had Bengali as mother tongue, died five years back during an expedition in the same location and wanted food to be put for him. She had no prior knowledge about the male identity. After food was put, the patient started moving out of the tent as if approaching the food while maintaining her position; weight supported on hips, heels of extended legs and palms towards the back. She stopped after moving a few steps, regained back her identity and started crying. She was unaware of her alleged possession but was aware of showing abnormal behaviour. She remained stable and slept well. She was not evacuated and kept under observation for next seven days during which she remained cheerful and resumed activities well. During a 12 month follow up, there was no recurrence or symptoms of any mental illness, though, she was emotionally labile to trivial issues.

\section{DISCUSSION}

Possession syndrome, a known disease entity, overlaps within medical and theological perspectives and sometimes labelled as a hoax. Possession syndrome meets modern medical criteria in having recognized symptom clusters and clinical findings but lacks recognized lab and imaging results. It is mostly attributed to a known disease entity though True Possession syndrome without associated mental illness has been reported. ${ }^{1-3}$ The fourth edition of the Diagnostic and Statistical Manual of Mental Disorders (DSM-IV), 45 places Dissociative trance disorder in Appendix B: Criteria Sets and Axes Provided for Further Study. Moreover Religious and Spiritual Problems are categorized under V62.89. The ICD-10 places F44 Dissociative (Conversion) Disorder and F44.3 Trance and possession disorders. Data is scanty and True Possession syndrome is not yet a recognized disease.

Historically, Esquirol described Possession syndrome as 'disease' and Freud attributed it to neurosis. ${ }^{4,5}$ It is hypothesized that when a person faces surmounting stress, s/he enters a possession-trance to solve the conflict. While the person is possessed, the stereotypical behaviour allows for release of repressed impulses and angry feelings, and catharsis alleviates anxiety and tension. ${ }^{6}$ Clinical features include non specific symptoms (headache, vomiting, abdominal pain, blindness, mutism), nebulous symptoms (phantom pain, violent body shaking resembling epilepsy, auditory, visual, tactile, olfactory and gustatory hallucinations), behavioural changes (abnormal talking, walking, facial expressions, body posturing, emotional instability, antisocial, suicidal, homicidal or violent behaviour) and paranormal features (exhibit a voice of opposite sex in an unknown language, supernatural strength, knowledge beyond the realm of awareness, paranormal motion of inanimate objects and self).

Diagnosis is difficult as possession like states are commonly seen in hysteria/conversion disorder (48.5\%), schizophrenia (24.3\%), depression (12.2\%), anxiety, mania, obsessive compulsive neurosis, Tourette syndrome, epilepsy, druginduced delirium, post traumatic stress disorder (PTSD), psychosis or dissociative identity disorder (DID). It is seen in lesions of basal ganglia, fronto-parietal lobes, limbic system hyperactivity and temporal lobe epilepsy. ${ }^{7-9}$ Malingering being 'possessed' to seek attention or individual benefits has been reported. It is commonly diagnosed as multiple personality disorder in the west, Voodoo possession in Africa and trance and possession disorder in Indian subcontinent. ${ }^{10}$ Exorcism resistant cases are reported to doctors, who are attributed to mental illness and treated by neuroleptics and associated therapy. ${ }^{1}$ Cases resistant to both exorcism and drugs are diagnosed as cases of mental insanity. The International Society for Study of Trauma and Dissociation has given guidelines for treatment of DID. ${ }^{11}$

Theological approach, more acceptable in certain cultures, promulgates Exorcism for treatment and caters to about $75 \%$ cases. ${ }^{12}$ Exorcism includes religious rituals to heighten suggestibility and is based on the psychotherapeutic principle of abreaction wherein undischarged and constrained emotion expressed covertly in the form of possession symptoms is released..$^{13}$ However, hypnotic suggestion may mask organic symptoms, behavior may be altered by post-hypnotic suggestion, and the placebo effect of treatment rituals is known. The Exorcists, at times, are able to tell whether a person has a mental illness and requires hospitalization and drug treatment or is truly possessed. Exorcism has been seen, by doctors as well, to bring profound mental and physical improvement leading to total remission as seen in this case. In true Possession syndrome, exorcism appears to be the only help possible. Various organizations including the International Association of Exorcists promulgate the ideology of differentiating possession from mental illness and performing exorcism only when the possession is not fully explained by a mental illness after a thorough psychiatric evaluation. Modern exorcisms are increasingly being performed in the presence of a doctor. 
There is a wide gap between the medical and theological ideology regarding Possession syndrome. There is a serious lack of understanding of medical pathology by laymen including theologians who tend to think in their own sphere of belief. Similarly, it is possible that doctors lack theological information constraining them to diagnose in their sphere of knowledge. Drug resistant cases of Possession syndrome have been cured by exorcism as well as people have died in the hands of exorcists for want of medical attention.

The possessed in this case was an educated working girl who was acclimatized and performing well in the course. She had no underlying mental illness, history of antecedent events, conflicts or stresses, prior knowledge about the deceased person which came as the spirit or prior exposure to the area. She brought forth new knowledge (gnosis). In an acclimatized girl, the presentation of headache was unusual and crying, uneasiness and fear were dramatic for the girl's composure. The symptoms were not relieved by usual therapy. There was no aura of healers as she had limited interaction with them. It was not apparent that the illness was ready to be healed in that setting. She exhibited markedly abnormal body posturing while she tried to go out of the tent, something even a diseased person would not attempt. There was a histrionic improvement after offering food. There was partial retrograde amnesia to possession.
There was no memory of exorcism nor any marks over her body. Malingering was not apparent. There were no residual effects in the days that followed while under observation. The possession was a single episode with no recurrences after exorcism, in a follow up period of 12 months. The exorcists had never performed any exorcisms before. They had retrograde partial amnesia towards exorcism and claimed that $80 \%$ of their actions were involuntary. However, there was cultural insight of such a problem in the girl as well as the exorcists. High altitude environment is stressful and hypoxia has been implicated in hallucinations. Tales from folklore mention transient possession of mountaineers, Phantom companion and the 'Yeti' or abominable snowman.

We, as doctors, being the most educated members of today's society, stand at a pedestal to develop a holistic approach of paranormal experiences so as to give better professional advice in Possession syndrome cases. The concept of possession should be observed as a disease condition and a harmonizing approach advocated. Theological perspective can be amalgamated with current scientific theory and practice, thereby complimenting existing concepts. Possession syndrome and exorcism may be incorporated into some paradigm of illness. Time will answer.

\section{REFERENCES}

1. Hale AS, Pinninti NR. Exorcism-resistant ghost possession treated with Clopenthixol. The British Journal of Psychiatry. 1994; 165: 386-388.

2. Gallagher RE. Among the Many Counterfeits: A Case of Demonic Possession. New Oxford Review ;2008. pg. 75 (3).

3. Peck MS. Glimpses of the Devil: A Psychiatrist's Personal Accounts of Possession, Exorcism, and Redemption. Free Press; 2005.

4. Esquirol JED. Mental Maladies. A Treatise on Insanity. Philadelphia: Lea \& Blanchard; 1845. [Reprinted New York: Hafner; 1965].

5. Freud S. A neurosis of demoniacal possession in the seventeenth century. The standard edition. Collected papers IV. London: Hogarth press; 1946.

6. Ee HK, Li PS, Kuan TC. A cross-cultural study of the possession-trance in Singapore. Aust NZ J Psychiatry. 1986; 20: 361-364.

7. Yap PM. The possession syndrome: a comparison of Hong Kong and France findings. J Ment Sci. 1960; 106: 114-137.

8. Basu S, Gupta SC, Akhtar S. Trance and Possession like symptoms in a case of CNS lesion: A Case Report. Indian J Psychiatry. 2002; 45(1): 65-67.

9. Chiu SN. Historical, religious and medical perspectives of possession phenomenon. Hong Kong Journal of Psychiatry. 2000; 10(1): 14-18.

10. Bhatia MS. An analysis of 60 cases of culture bound syndromes. Ind J Med Sci. 1999; 53(4):149-152.

11. International Society for the Study of Trauma and Dissociation (2011). Guidelines for treating Dissociative Identity Disorder in Adults, Third Revision. Journal of Trauma and Dissociation. 12:2; 115-187.

12. Campion J, Bhugra D. Religious healing in South India. Paper presented at the World Association of Social Psychiatry meeting. Germany, Hamburg; June 1994.

13. Sargant W. The mind possessed: A Physiology of Possession, Mysticism and Faith Healing. London: Heinemann;1973. 